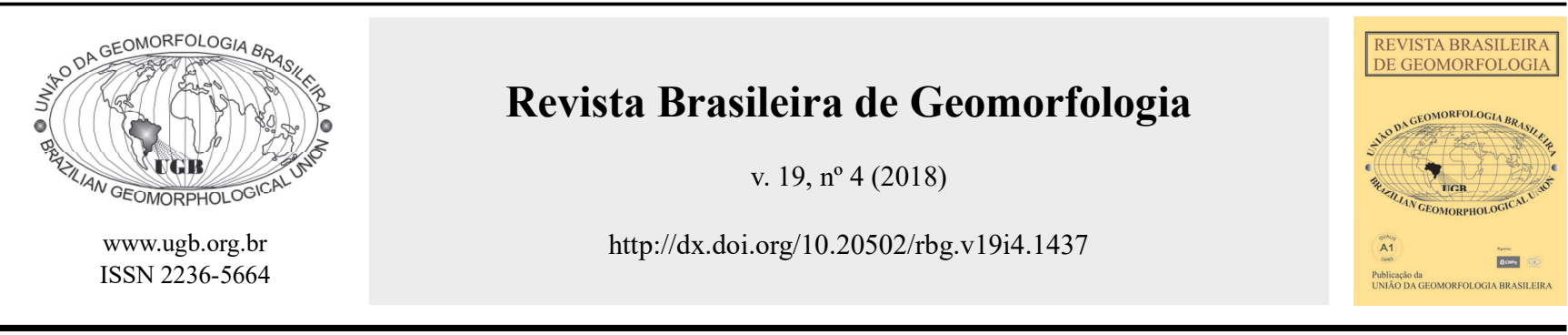

\title{
PROCESSOS DE ENCOURAÇAMENTO DE LEITOS FLUVIAIS: SISTEMATIZAÇÃO DE BASES TEÓRICAS E ESTUDO DE CASO NA SERRA DO ESPINHAÇO MERIDIONAL (MG)
}

\section{BED ARMOURING PROCESSES: SYSTEMATIZATION OF THEORETICAL BASES AND CASE STUDY IN SOUTHERN SERRA DO ESPINHAÇO (MG)}

\author{
Guilherme Eduardo Macedo Cota \\ Departamento de Geografia, Universidade Federal de Minas Gerais \\ Av. Antônio Carlos, 6627, Belo Horizonte, Minas Gerais. CEP: 31270-901. Brasil \\ E-mail: guilhermebhmg@hotmail.com \\ Antônio Pereira Magalhães Júnior \\ Departamento de Geografia, Universidade Federal de Minas Gerais \\ Av. Antônio Carlos, 6627, Belo Horizonte, Minas Gerais. CEP: 31270-901. Brasil \\ E-mail: antonio.magalhaes.ufmg@gmail.com
}

Luiz Fernando de Paula Barros

Departamento de Geografia, Universidade Federal de Minas Gerais Av. Antônio Carlos, 6627, Belo Horizonte, Minas Gerais. CEP: 31270-901. Brasil

E-mail:luizfpbarros@yahoo.com.br

Informações sobre o Artigo

Recebido (Received):

01/06/2018

Aceito (Accepted):

$09 / 08 / 2018$

\section{Palavras-chave:}

Encouraçamento Fluvial; Córrego do Rio Grande; Serra do Espinhaço Meridional/MG.

Keywords:

Bed Armouring; Rio Grande Stream; Southern Serra do Espinhaço/MG.

\section{Resumo:}

Os processos de encouraçamento se referem à presença de sedimentos imóveis (ou imediatamente imóveis) nas calhas fluviais, impedindo a remoção de grãos potencialmente transportáveis. Assim, é formado um pavimento detrítico (cluster) na superfície do leito, que oferece grande resistência aos processos abrasivos. Apesar de serem amplamente discutidos na literatura internacional, há poucas contribuições em âmbito nacional para os estudos sobre encouraçamento. Nesse sentido, o presente trabalho propõe, a partir de uma sistematização de bases teóricas, investigar a ocorrência dos processos de encouraçamento sob a ótica geomorfológica. Para tanto, o Córrego do Rio Grande (Serra do Espinhaço Meridional, MG) é adotado como estudo de caso. A partir da investigação in loco dos pavimentos detríticos que caracterizam os processos de encouraçamento, foi possível associar o rebatimento da presença dos sedimentos imóveis para as condições hidrogeomorfológicas do canal fluvial em três dos quatro segmentos investigados. Evidências de campo apontam que a dinâmica hidrogeomorfológica consequente da presença dos clusters é caracterizada por uma morfologia em poçocorredeira e por uma morfodinâmica marcada por processos de meandramento. 


\begin{abstract}
:
The bed armouring processes refer to the presence of immobile (or immediately immobile) sediments in the river channels, preventing the removal of potentially transportable grains. Thus, a detrital floor is formed on the bed surface, which offers great resistance to the abrasive processes. Although widely discussed in the international literature, there are few national contributions to bed armouring studies. The present work proposes, from a systematization of the theoretical bases, to investigate the occurrence of the armouring processes from the geomorphological point of view. In order to do so, the Rio Grande Stream (Southern Serra do Espinhaço, MG) is adopted as a case study. Based on the in situ investigation of the detrital pavements that characterize the bed armouring processes, it was possible to associate the bending of the presence of the immobile sediments to the hydrogeomorphological conditions of the fluvial channel in three of the four segments investigated. Field evidence indicates the hydrogeomorphological dynamics consequent to the presence of the clusters is characterized by morphology in riffle-pools and by a morphodynamics marked by meandering processes.
\end{abstract}

\section{Introdução}

Os processos de encouraçamento de leitos fluviais (bed armouring) se referem à presença de sedimentos imóveis (ou imediatamente imóveis) nas calhas fluviais, impedindo a remoção de grãos potencialmente transportáveis (BRIDGE, 2003). Desse modo, é formado um pavimento detrítico na superfície do leito do rio, que oferece grande resistência aos processos abrasivos (FRINGS, 2008; GRANT, 2012). Assim, somente os materiais de granulometria mais fina (argiloso a arenoso) que recobrem estes pavimentos são transportados (CHARLTON, 2008).

O equilíbrio hidrossedimentológico, portanto, é alterado, gerando uma perturbação no sistema fluvial, tendo em vista que novas relações entre produção, transporte e deposição de sedimentos passam a vigorar. As novas condições de transporte de material, por conseguinte, influenciam e modificam a geometria do canal, que num processo de retroalimentação também influenciam a vazão e o transporte de sedimentos. Consequentemente, o impacto da imobilização dos sedimentos pode ocasionar um colapso na estabilidade do sistema fluvial. O canal tende a migrar lateralmente e a erodir suas margens, aumentando a largura do curso d'água (VERICAT et al., 2006; SANTOS et al., 2008).

Apesar de serem mais comuns na literatura internacional (CHIN, 1999; BRIDGE, 2003; CHARLTON, 2008), são raros os trabalhos que se debruçam sobre propostas metodológicas para o estudo do encouraçamento de calhas fluviais, bem como sobre a gênese dos pavimentos detríticos. Tanto que, consequentemente, não há uma única definição para determinar o que seriam leitos fluviais encouraçados, bem como sobre sua abrangência temporal e espacial.
Em âmbito nacional, os estudos sobre encouraçamento são escassos, com destaque para os trabalhos de Magalhães Júnior et al. (2008) e Stevaux et al. (2009), que identificam trechos de vale encouraçados e os correlacionam com a litologia, no caso do primeiro, e com a interferência de atividades antrópicas, no caso do segundo.

Diante da carência de estudos relativos à temática do encouraçamento no âmbito da geomorfologia fluvial, o presente trabalho se propõe a discutir as bases teóricoconceituais sobre processos de encouraçamento de calhas fluviais na literatura nacional e internacional, investigando os seus principais problemas e desafios conceituais numa abordagem geomorfológica. Além disso, o trabalho objetiva apresentar reflexões sobre a influência dos pavimentos detríticos para a dinâmica atual dos cursos d'água. De modo a complementar a abordagem teórica sobre encouraçamento e fomentar a discussão sobre a dinâmica fluvial de rios em contextos montanhosos, o Córrego do Rio Grande (Serra do Espinhaço Meridional) é adotado como estudo de caso. Para tanto, são caracterizados os pavimentos encontrados quanto aos diferentes aspectos de localização, arranjo espacial, granulometria e litologia predominante.

Diversos trabalhos de cunho geomorfológico têm sido realizados no domínio geológico-geomorfológico da Depressão de Gouveia, na Serra do Espinhaço Meridional (ALMEIDA-ABREU, 1995; SAADI, 1995; SALGADO, 2002; SALGADO \& VALADÃO, 2003; REZENDE et al., 2010; AUGUSTIN et al., 2011; LEÃO et al., 2012; MAGALHÃES JÚNIOR et al., 2015). No entanto, são poucos os trabalhos publicados em periódicos que tratam diretamente da geomorfologia fluvial desse domínio. 


\section{Bases conceituais e teóricas acerca dos processos de encouraçamento (bed armouring)}

A literatura, de maneira geral, descreve os processos de encouraçamento fluvial como a formação de um pavimento detrítico no leito de um curso d'água que, por alterações na capacidade e/ou competência do fluxo, mantém seus grãos imóveis ou temporariamente imóveis (BRIDGE, 2003; GOUDIE, 2004; ALMEDEIJ \& DIPLAS, 2005; VERICAT et al., 2006; FRINGS, 2008).

Nos estudos sobre encouraçamento e gênese de couraças ferruginosas pleistocênicas de origem fluvial no Quadrilátero Ferrífero (Minas Gerais), Magalhães Júnior et al. (2008) e Barros et al. (2016) destacam que a alta concentração de ferro dissolvido das formações ferríferas bandadas (Banded Iron Formations - BIF's) e sua posterior precipitação em ambientes de fundos de vale - pela oscilação do nível freático - favorecem a cimentação ferruginosa do material mais grosso. Assim, o encouraçamento não é compreendido apenas pelos sedimentos "soltos", porém imóveis sobre o leito, mas também pela cimentação ferruginosa destes materiais que ficam mais resistentes à ação do fluxo.

Charlton (2008) e Curran \& Tan (2010) destacam que o fenômeno de encouraçamento está associado a uma redução das vazões por períodos estendidos, tornando o fluxo incapaz de transportar os materiais de granulometria mais grossa (seixo e cascalho). Quando esse material é depositado na calha (Figura 1), há um aumento da rugosidade do leito e a diminuição da força erosiva do fluido, o que decorre do atrito do fluxo com as partículas de granulometria variada. Associadas às irregularidades do canal, estas partículas requerem maior energia para o seu transporte (CHARLTON, 2008; CURRAN \& TAN, 2010; HEAYS, 2011). Consoante, estes depósitos imóveis em ambiente de calha geram clusters, identificados como agrupamentos de sedimentos de granulometria variada que permanecem imóveis no leito fluvial (BILLI, 1988; CURRAN \& TAN, 2010).

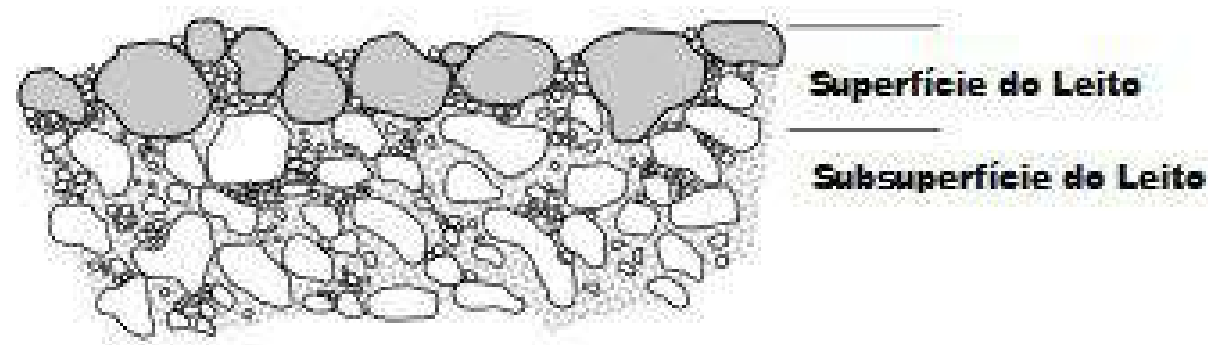

Figura 1 - Representação do mecanismo básico de encouraçamento fluvial. Fonte: Adaptado de Almedeij \& Diplas (2005).

O pavimento detrítico que recobre o leito fluvial limita e/ou impede que processos abrasivos ocorram, cessando, mesmo que parcialmente, as taxas de incisão vertical do canal. Os leitos fluviais encouraçados, portanto, tendem a dispensar a sua energia se expandindo ou migrando lateralmente (XU, 1996; VERICAT et al. 2006).

A gênese dos processos de encouraçamento é abordada em poucos trabalhos, estando geralmente associada às variações nos inputs e outputs de energia do sistema e a alterações nos níveis de base que modificam a capacidade e competência dos cursos d'água, podendo favorecer processos de agradação e de formação de um pavimento detrítico no leito fluvial (BENN \& ERSKINE, 1994; VERICAT et al., 2006).

Variações no fornecimento de material sedimentar para os cursos d'água também podem promover alterações nas taxas de transporte de material de leito. Cursos d'água com elevado aporte sedimentar podem responder com taxas de transporte de carga de leito diferentes de cursos d'água com pouco fornecimento de material detrítico. Deste modo, é possível inferir que, durante um momento de maior agradação de um vale fluvial, pode ocorrer o entulhamento da seção do canal com sedimentos mais grossos do que a capacidade e a competência do curso d'água, favorecendo a ocorrência de processos de encouraçamento. Esses processos são predominantes em regiões montanhosas, onde há o fornecimento de carga de leito grossa e mal classificada (LEOPOLD et al., 1964; GOUDIE, 2004). Por sua vez, vales com encostas íngremes e com ausência de vegetação podem concentrar processos mecânicos, sobretudo no transporte de cascalho e areia para os fundos de vale. 
Conquanto, parte significativa dos trabalhos investigados se preocupa com aspectos hidrológicos para definir as condições de fluxo necessárias para garantir o equilíbrio dos pavimentos detríticos e para romper a camada de sedimentos imóveis sobre o leito (LARONNE et al., 1994; EMMETT \& WOLMAN, 2001; WILCOCK \& DETEMPLE, 2005; VERICAT et al., 2006). Deste modo, há uma subvalorização dos processos geomorfológicos e suas relações com as alterações hidrossedimentológicas, em prol de aspectos hidrológicos.

No que tange à escala temporal para formação dos pavimentos detríticos, diversos trabalhos associam sua ocorrência a uma diminuição da vazão fluvial durante períodos secos, quando não há competência para carregar sedimentos grossos (GOMEZ, 1983; CHARLTON, 2008; CURRAN \& TAN, 2010). Sob esta lógica, seria possível associar os processos de encouraçamento à variação sazonal no regime pluviométrico. No entanto, Billi (1988) em seu estudo na porção central da Itália mostra que não é possível estabelecer uma temporalidade precisa para a ocorrência de processos de encouraçamento, pois mesmo durante eventos de inundação, os clusters formados podem não se alterar. Ele ainda afirma que a taxa de destruição e (re)construção dos clusters não permanece igual a cada evento de inundação.

Deste modo, a identificação de trechos encouraçados em campo é um desafio complexo. A associação do encouraçamento com sedimentos imóveis no leito não pode ser realizada sem um monitoramento temporalmente significativo, que contemple a dinâmica hídrica sazonal e os eventos extremos com tempos de recorrência variados. Torna-se necessária uma análise acerca da estabilidade dos clusters ao longo do tempo. Não obstante, mesmo não havendo uma escala temporal específica para determinar se um leito está encouraçado ou não, a afirmação de diversos autores que os sedimentos permanecem imóveis durante baixos fluxos leva a entender que os processos de encouraçamento estão associados a estas condições, apesar de, conforme destaca Billi (1988), trechos encouraçados poderem permanecer intactos mesmo em períodos de maior fluxo.

Numa tentativa de associar leitos encouraçados às mudanças na morfologia de canais, é possível pensar em uma escala temporal mais ampla para a estabilidade dos pavimentos detríticos. Neste caso, além das condições de fluxo, transporte, deposição e descarga sedimentar, também devem ser consideradas outras variáveis, como o material constituinte das margens que, por sua vez, determina sua capacidade de coesão e a atuação dos processos de acresção lateral (SCHUMM \& KAHN, 1972). No entanto, não há nenhum postulado metodológico para determinação de trechos encouraçados a partir de mudanças na morfologia de canais.

No que tange à disposição espacial dos clusters, Heays (2011) afirma que estes agrupamentos de sedimentos são gerados pelo transporte seletivo que caracteriza os pavimentos detríticos, sendo mais estáveis que os materiais circundantes e gerando diversas microformas deposicionais nos leitos. Consoante, é possível inferir que, ao menos espacialmente, trechos encouraçados podem estar associados à ocorrência destas microformas. Em seu estudo sobre a formação destes agrupamentos de sedimentos, Strom et al. (2005) e Hendrick et al. (2010) identificam nove tipos de clusters principais (Figura 2).
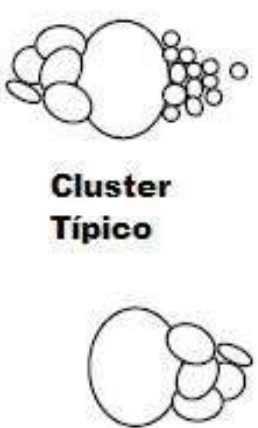

Upstream

Triangle
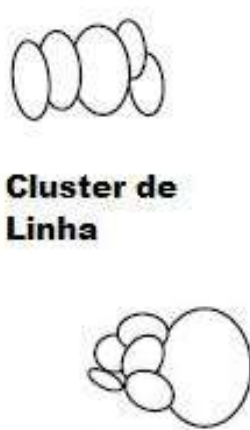

Downstream

Triangle

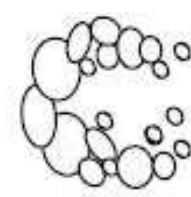

Comet

Cluster
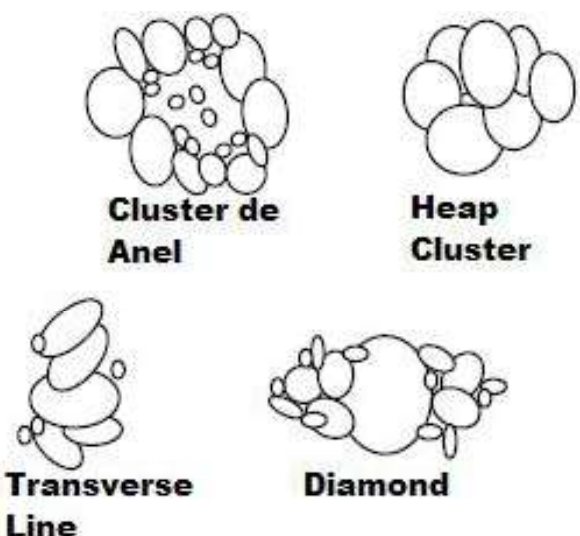

Diamond

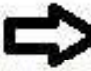

Sentido do Fluxo

Figura 2 - Diferentes tipos de clusters. Fonte: Adaptado de Strom et al. (2005) e Hendrick et al. (2010) por Heays (2011). 
A presença de clusters, portanto, fomenta os processos de oscilação da energia dos fluxos na medida em que promove sua convergência no contato com os clusters e posterior divergência à jusante dos mesmos (FERNANDEZ, 2009). Este processo vai de encontro à discussão de Montgomery \& Buffington (1997), que afirmam que esta oscilação nas condições de fluxo é responsável pela configuração de sequências de poçocorredeira (pool-riffle) e que leitos fluviais com estas características comumente encontram-se encouraçados.

A configuração espacial destes clusters, portanto, está associada às células de fluxos internos (convergência nos rifles e divergência nos pools). Sob esta ótica, leitos encouraçados não precisam necessariamente estar associados somente aos materiais imóveis in situ como destacam BRIDGE (2003), ALMEDEIJ \& DIPLAS (2005), VERICAT et al. (2006), GOUDIE (2004) e FRINGS (2008), mas sim a uma morfologia de leito que caracterize segmentos encouraçados. Montgomery
\& Buffington (1997), Magalhães Júnior et al. (2008) e Messias \& Magalhães Júnior (2014) corroboram com esta afirmação ao associarem a ocorrência de processos de encouraçamento a leitos com morfologia de poçocorredeira.

\section{Caracterização da área}

A bacia hidrográfica do Córrego do Rio Grande está inserida no segmento médio da Serra do Espinhaço Meridional, que se estende do sul do Planalto de Diamantina ao norte da Serra do Cipó (REZENDE et al., 2010; LEÃO et al., 2012). Dada a sua elevada amplitude altimétrica, a Serra do Espinhaço Meridional serve como divisor de águas para três importantes bacias brasileiras: as dos rios Doce e Jequitinhonha, que pertencem à fachada atlântica brasileira, e a do rio São Francisco, que possui vasta área de drenagem no interior continental. Nesta se situa a bacia do Córrego do Rio Grande (Figura 3).
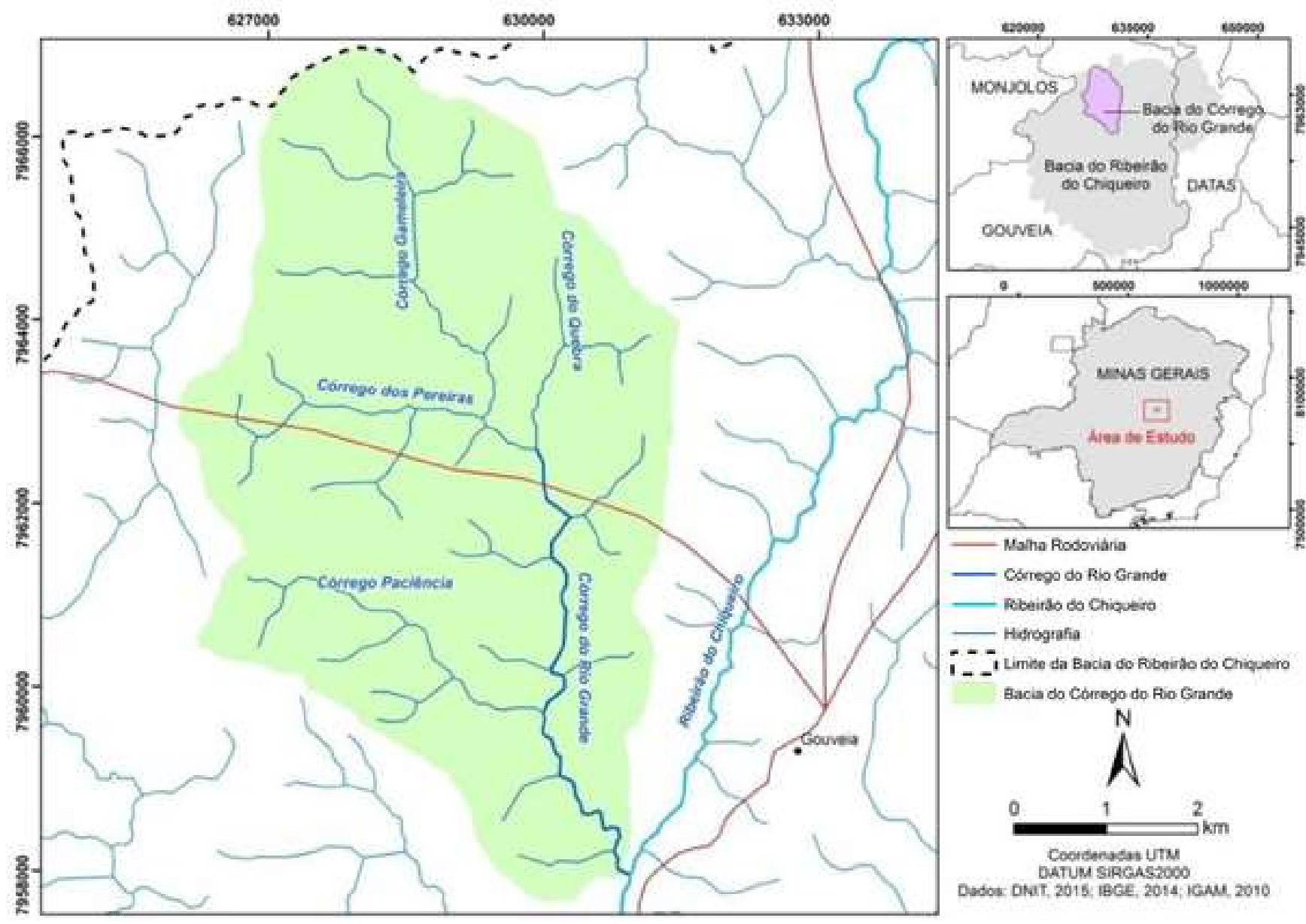

Figura 3 - Localização da bacia do Córrego do Rio Grande. Fonte: Elaboração dos autores. 
O Córrego do Rio Grande drena parte do Complexo de Gouveia no sentido norte-sul (Figura 4), possuindo dinâmica geomorfológica fortemente marcada pela erosão diferencial. As rochas do Supergrupo Espinhaço (Paleo/Mesoproterozoico) e do Supergrupo Rio Paraúna (idade Arqueana a Paleoproterozóica), sobretudo os quartzitos, oferecem maior resistência aos processos de intemperismo do que as rochas do Complexo de Gouveia, que são compostas principalmente por granitos e gnaisses arqueanos (SALGADO \& VALADÃO, 2003).
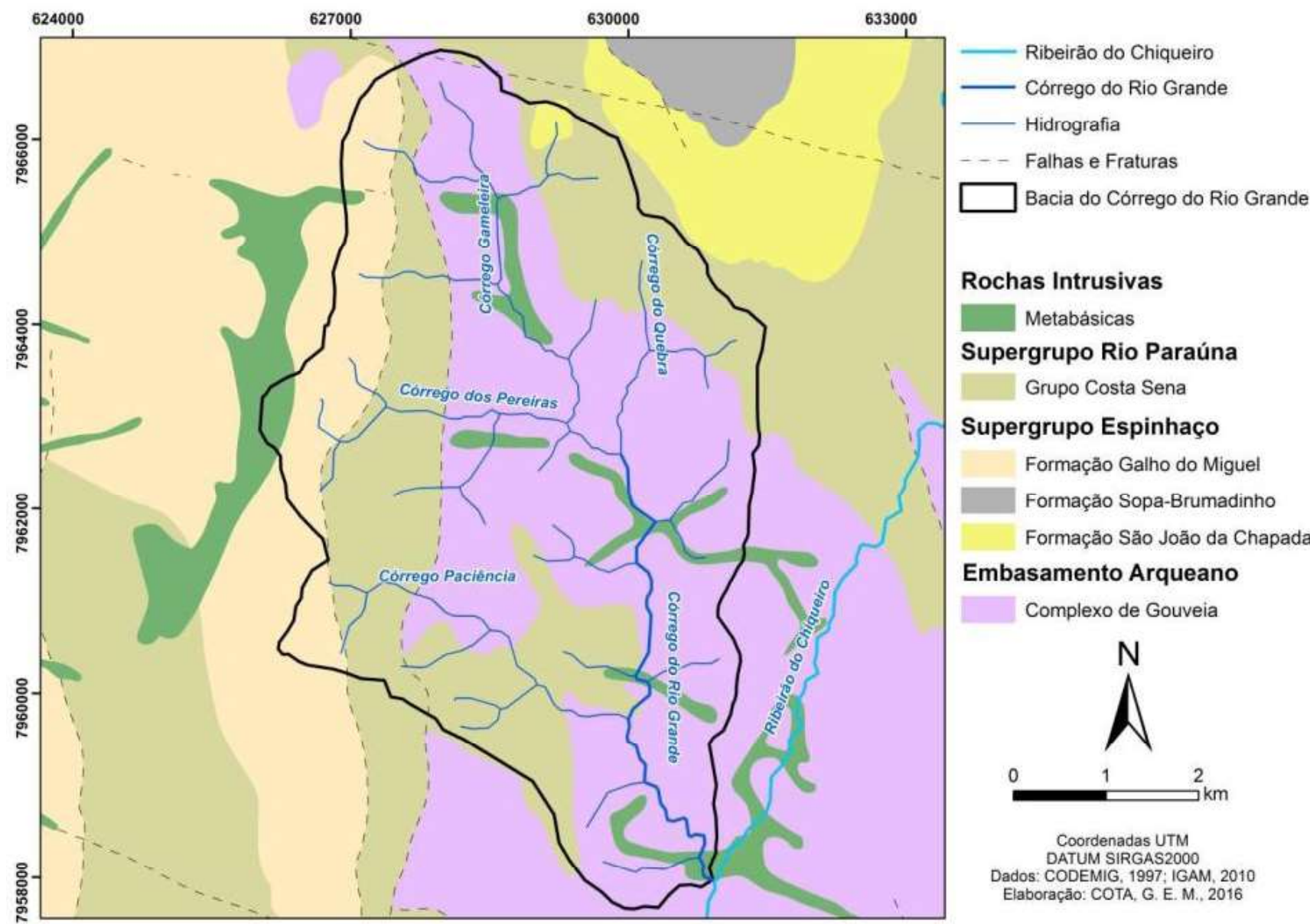

Rochas Intrusivas

Metabásicas

Supergrupo Rio Paraúna

Grupo Costa Sena

Supergrupo Espinhaço

Formação Galho do Miguel

Formação Sopa-Brumadinho

Formaçăo Săo João da Chapada

Embasamento Arqueano

Complexo de Gouveia

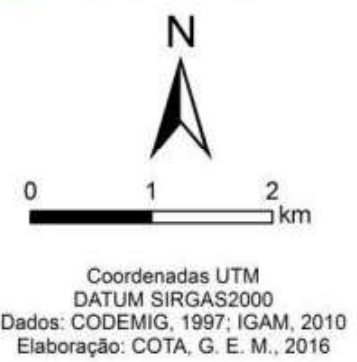

Figura 4 - Mapa geológico da bacia do Córrego do Rio Grande. Fonte: Elaboração dos autores.

Salgado \& Valadão (2003) destacam dois compartimentos geomorfológicos para a área: a superfície de cimeira, onde predominam os quartzitos e que circunda toda a área deprimida da Depressão de Gouveia; e o piso da depressão, cuja composição litológica é fortemente marcada por granitos e gnaisses e que corresponde à porção do relevo rebaixada em relação ao seu entorno. Encontram-se ainda intrusões de rochas metabásicas, predominantemente sob a forma de diques e soleiras (SALGADO \& VALADÃO, 2003).

\section{Procedimentos metodológicos}

Os procedimentos metodológicos adotados para investigação dos processos de encouraçamento no Córrego do Rio Grande foram divididos em etapa de gabinete e etapa de campo. Os procedimentos realizados em gabinete se referem à coleta de informações sobre a área de estudo, visando um conhecimento do "estado-daarte" das pesquisas na região, bem como o levantamento dos dados cartográficos disponíveis e sua posterior manipulação a partir do software ArcGIS®, em sua versão 10.1. A partir de imagens de satélite de alta resolução do software Google Earth Pro ${ }^{\circledR}$, foram executadas investigações acerca da configuração morfológica do leito e dos ambientes marginais, visando identificar formas deposicionais fluviais (barras de canal, planície, níveis deposicionais aluviais) que indicassem prováveis ambientes para a formação de pavimentos detríticos, a exemplo da morfologia de leito em poço-corredeira.

Trabalhos de campo foram realizados para uma 
melhor compreensão das características físicas da área, bem como para a identificação in loco de segmentos fluviais potencialmente encouraçados. Para tanto, foi investigado visualmente a disposição espacial dos pavimentos detríticos (leito em cascalho) e mapeados os locais de sua ocorrência em relação ao contexto do vale. Após a identificação e mapeamento dos segmentos fluviais com pavimentos detríticos, foram investigadas as características gerais destes trechos, bem como as diferenças para os segmentos sem pavimentos. Foi elaborado um check list e analisadas características no que tange aos ambientes marginais, posição na bacia/vale e relação com afluentes, tomando como modelo as descrições de leito feitas por Rosgen (1994) e Brierley \& Fryirs (2005). A partir das informações sistematizadas em campo, foram elaborados blocos diagrama com o auxílio do software CorelDRAW@, em sua versão 11.633, para ilustrar os pavimentos detríticos dos segmentos fluviais investigados.

\section{Caracterização das ocorrências de pavimentos detríticos em calhas fluviais locais}

A partir da sistematização das informações obtidas em campo, foi possível selecionar quatro segmentos fluviais para investigação, sendo os resultados organizados sob dois enfoques: um baseado em análises práticas (litologias presentes, material de leito, grau de arredondamento dos seixos e intervenções antrópicas) e outro sob a perspectiva de observação e descrição da morfologia e dos depósitos identificados (formas de leito e barras de canal).

No que tange às análises práticas, não foram encontradas diferenças importantes entre os trechos investigados. As evidências de campo indicam que em todos os segmentos analisados há o predomínio de seixos de quartzo nas calhas, intercalados, em menor quantidade, com seixos de quartzito e granitóides.

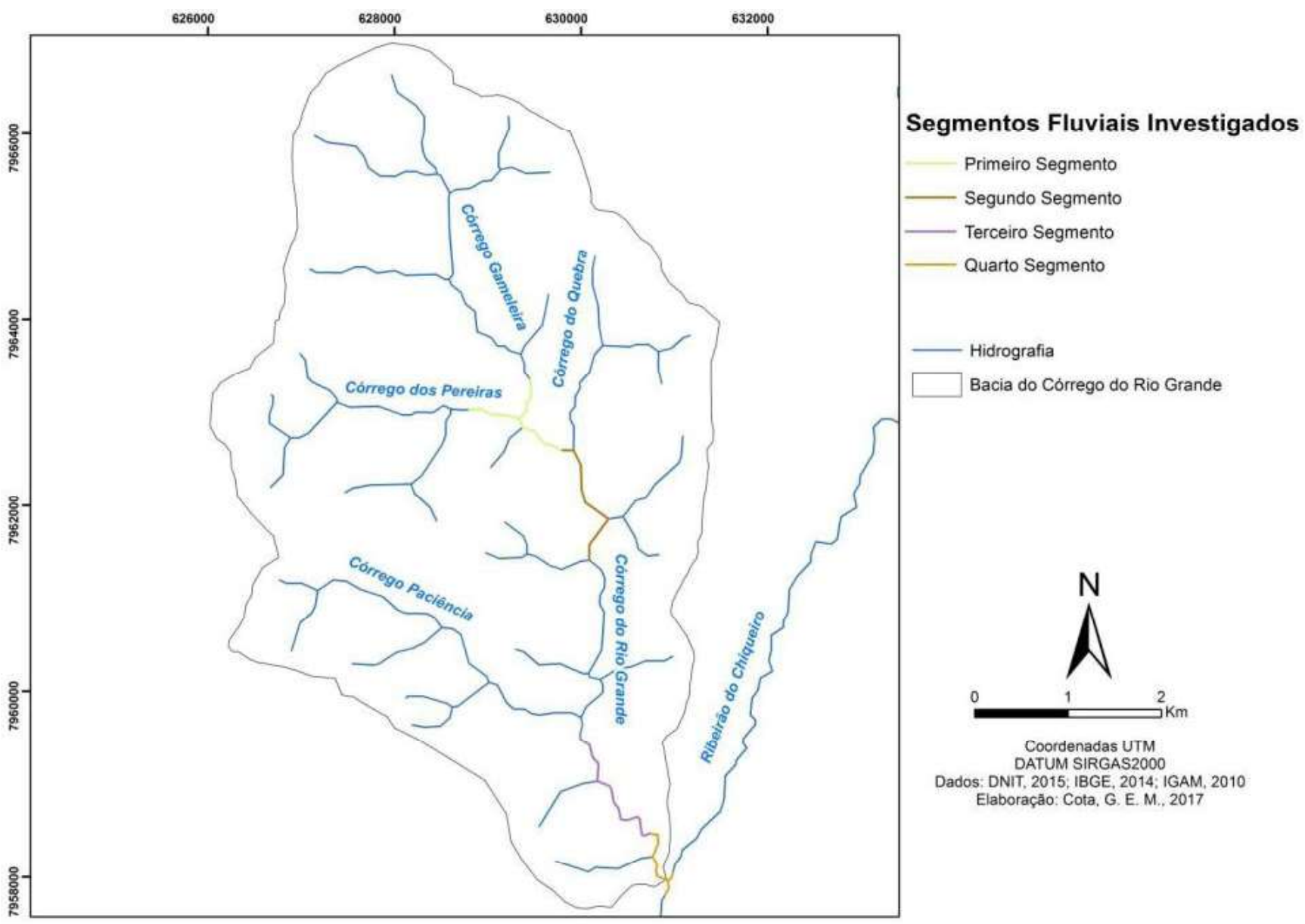

Figura 5 - Segmentos fluviais investigados na bacia do Córrego do Rio Grande. Fonte: Elaboração dos autores. 
O grau de arredondamento dos materiais varia desde sub-arredondado a sub-anguloso, o que pode indicar um aporte rápido e pouca mobilização (proximidade das áreas-fonte). Deste modo, os materiais não teriam tido tempo suficiente para um maior desgaste e arredondamento ou estariam estacionados na calha por longos períodos. Mesmo nos locais onde o substrato litológico se altera, como nos afloramentos de rochas metabásicas, a litologia da carga de leito (seixos e cascalhos) e seu grau de arredondamento permanecem inalterados.

A partir da observação e descrição, foram elaborados blocos diagramas síntese para as quatro configurações de leitos encontradas. Destaca-se que tais representações gráficas foram elaboradas visando a identificação de evidências geomorfológicas da ocorrência de pavimentos detríticos, ou seja, uma análise com enfoque em ambiente de calha. Assim, a representação de outros elementos constituintes do vale fluvial, como encostas e níveis deposicionais fluviais, não correspondem às dimensões reais, seja em sua extensão ou declividade.

O primeiro segmento se localiza no alto-médio curso, logo após a confluência do Córrego Gameleira com o Córrego dos Pereiras (Figura 6).

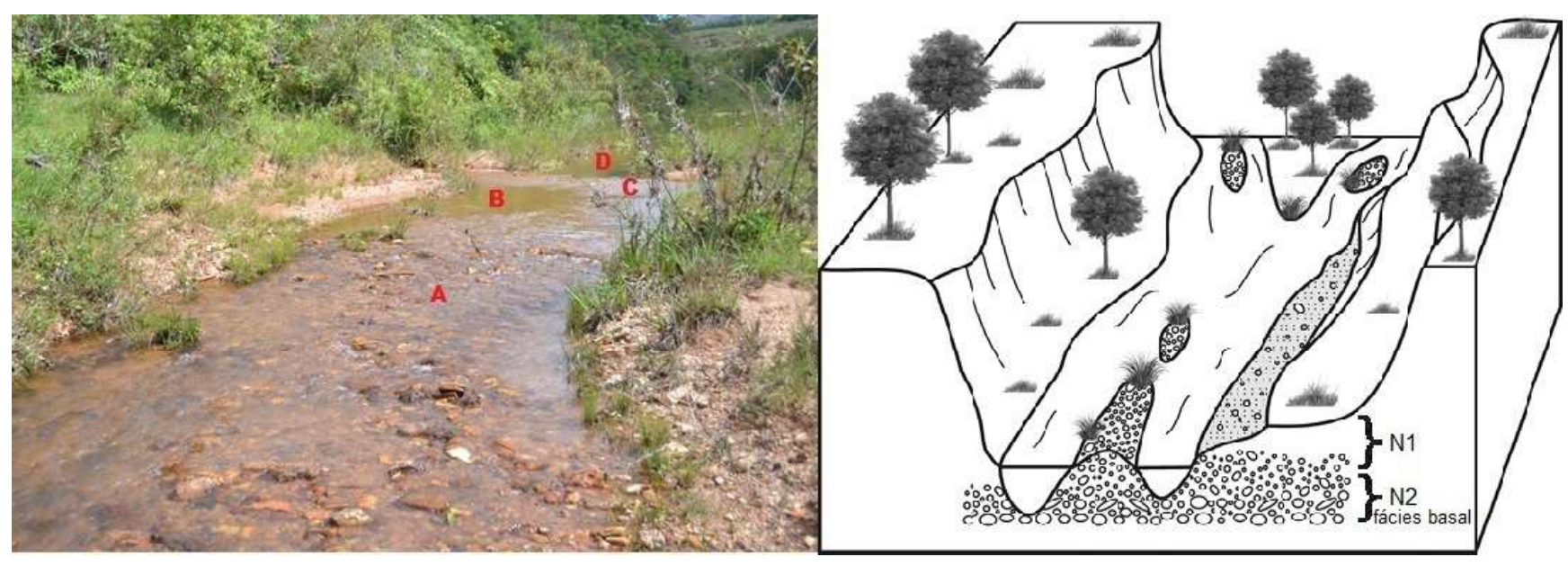

Figura 6 - Foto e bloco diagrama do primeiro segmento investigado-A e C correspondem às corredeiras, $B$ e $D$ correspondem aos poços. Fonte: Elaboração dos autores.

O predomínio de seixos e cascalhos no leito pode indicar que este material mais grosso permanece imóvel ou é transportado minimamente nos períodos de maiores vazões. Tal observação corrobora as afirmações de Bridge (2003), Goudie (2004), Almedeij \& Diplas (2005), Vericat et al. (2006) e Frings (2008) que consideram esses materiais grossos e imóveis em ambientes de calha como associados a encouraçamento.

No primeiro segmento o córrego apresenta padrão sinuoso, com morfologia de leito caracterizada por uma sucessão de poços e corredeiras. Nos trechos referentes aos clusters (corredeiras), o material pavimentado se estende pela base da planície (N1) e possivelmente também corresponde à base do nível deposicional inferior (N2). Assim, a calha atual permanece na mesma posição da base desse nível, o qual é, possivelmente, recoberto pela planície (sedimentação atual). Também são encontradas barras de canal laterais compostas por areia, seixos e cascalhos.

O segundo segmento se localiza no médio curso, próximo à confluência do Córrego Gameleira com o Córrego do Quebra, formando o Córrego do Rio Grande (Figura 7). Apesar de situado logo à jusante do primeiro segmento investigado, este trecho é caracterizado pelo afloramento de rochas metabásicas que, por sua vez, condicionam a morfologia e a morfodinâmica fluvial. Justamente por compreenderem diques e sills, os trechos em rochas metabásicas sofrem significativo controle estrutural, apresentando padrão morfológico majoritariamente retilíneo e ausência de planícies em ambas as margens. A maior energia e a incisão vertical do canal podem explicar a não formação ou a não preservação de níveis deposicionais neste trecho. 


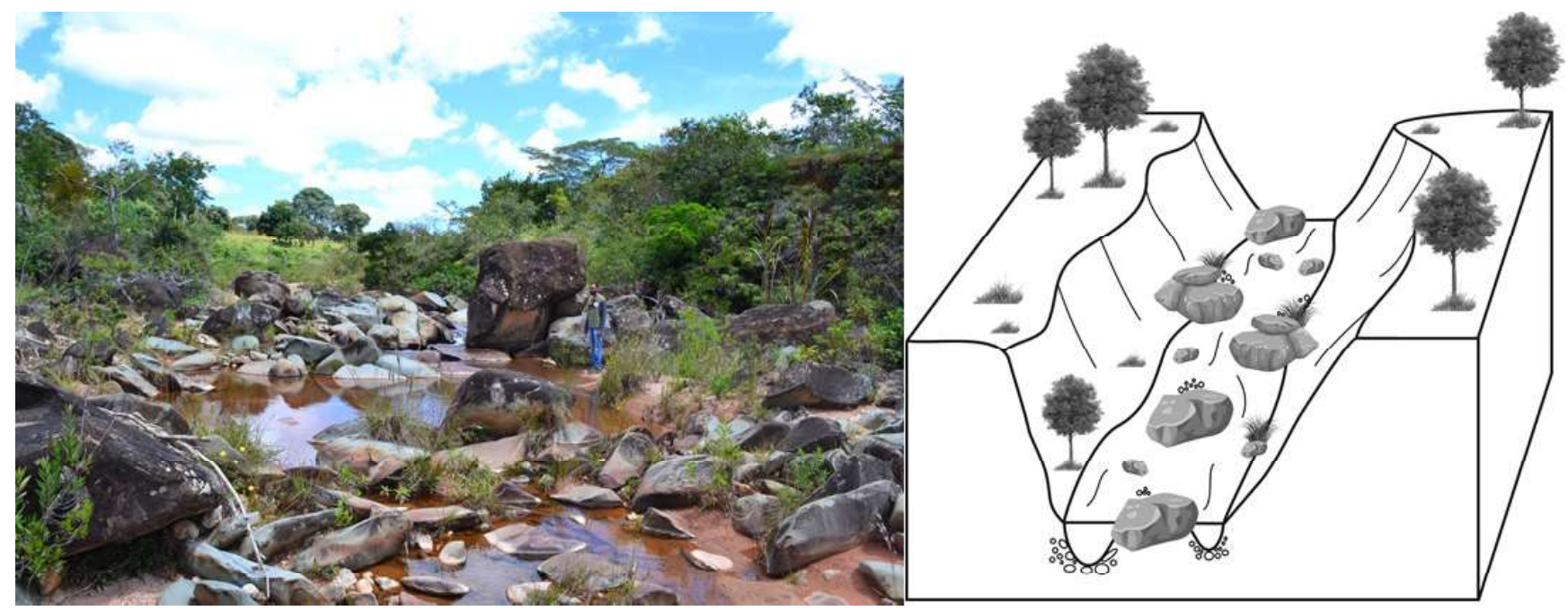

Figura 7 - Foto e bloco diagrama do segundo segmento investigado. Fonte: Elaboração dos autores.

Apesar da presença de seixos e cascalhos na calha, as condições de maior energia não favorecem que a dinâmica de fluxo seja controlada pelos sedimentos. A convergência do fluxo nas corredeiras e a divergência nos poços não ocorre, e a morfologia de leito se configura em step-pools (MONTGOMERY \& BUFFINGTON, 1997). Deste modo, não é possível afirmar que a estabilidade da carga de leito seja consequência da baixa capacidade e competência, mas sim da presença de afloramentos rochosos que agem como pequenas soleiras, retendo os sedimentos mais grossos no contato com a rocha.

O terceiro segmento fluvial situa-se no médiobaixo curso, sendo marcado por intercessões de leitos aluviais e rochosos. Diferentemente do segmento anterior, os afloramentos rochosos correspondem ao Complexo de Gouveia, particularmente granitos e gnaisses.

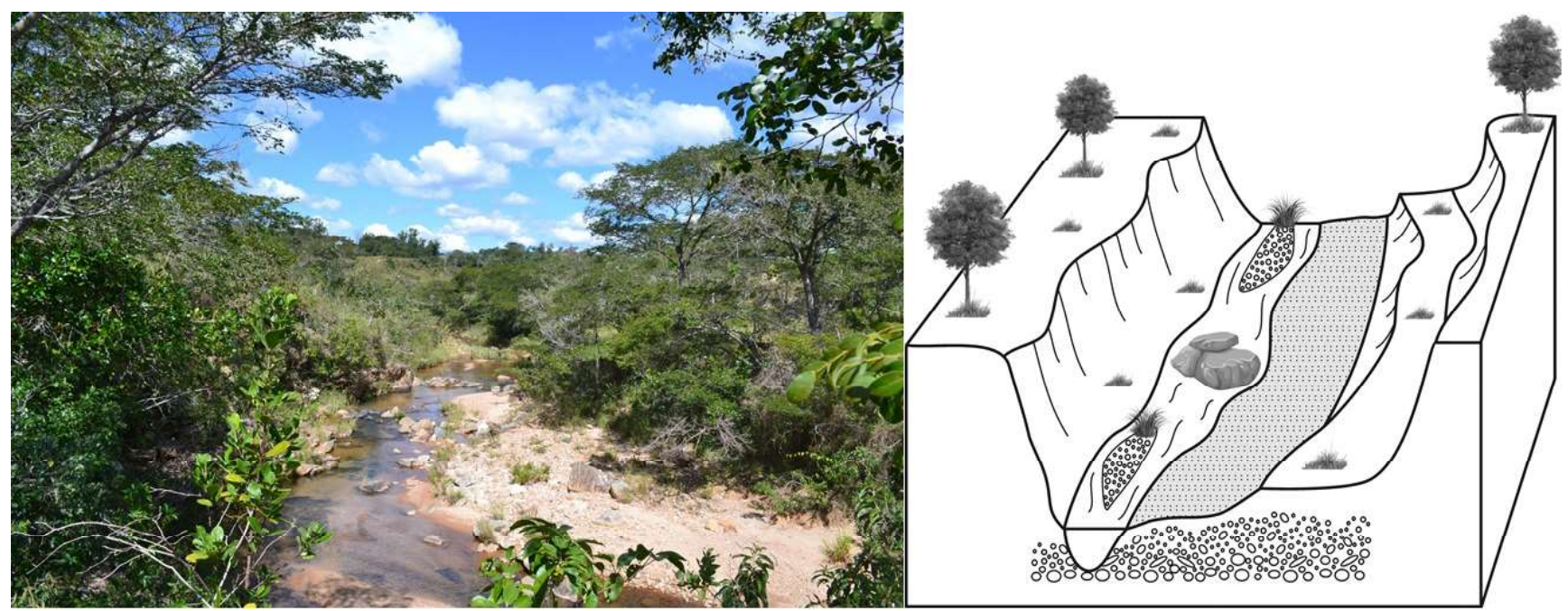

Figura 8 - Foto e bloco diagrama do terceiro segmento - trecho em step-pool. Fonte: Elaboração dos autores.

A interseção entre leito rochoso e aluvial se altera em poucos metros, não sendo possível distinguir uma única morfologia de leito característica para o segmento em questão. Contudo, se analisado com maior detalhamento, é possível afirmar que a morfologia nos trechos aluviais, compostos principalmente por seixos e cascalhos, corresponde a poço-corredeira (MONTGOMERY \& BUFFINGTON, 1997), enquanto que nos trechos em leito rochoso corresponde a steppool (MONTGOMERY \& BUFFINGTON, op. cit.). 
Se analisado em menor escala (longitudinalmente), é possível afirmar que a morfologia do leito é caracterizada por sucessivos trechos em poço-corredeira e em step-pools, mesmo que a variação entre eles se dê em curtas distâncias.

O canal apresenta padrão sinuoso, indicando que o possível controle resultante da presença de afloramentos rochosos não é significativo. Rosgen (1994) associa a ocorrência de poços-corredeiras e step-pools às classes de declividade propostas por Grant et al. (1990), sendo leitos com declividade abaixo de $2 \%$ para os primeiros e entre $4 \%$ e $40 \%$ para os segundos. Tal análise se baseia principalmente no gradiente dos canais, não considerando outros fatores como o regime fluvial, influência de tributários, aporte sedimentar, oscilações climáticas, presença de soleiras e outros níveis de base que podem, em certa escala, favorecer o surgimento dessas morfologias de leito.

Além de Rosgen (1994), Montgomery \& Buffington
(1997) também buscam associar a morfologia em steppools com a declividade $(0.02$ a $0.08 \mathrm{~m} / \mathrm{m})$ e com leitos confinados por encostas (encaixados). As observações de campo não identificaram encaixamento e declividade significativa aparente para o terceiro segmento. Baseado nas contribuições dos referidos autores, é possível afirmar que a morfodinâmica do curso d'água não é controlada pela presença dos step-pools, mas sim por poços-corredeiras que estão associadas a uma maior sinuosidade.

No quarto segmento foram investigadas as contribuições do Córrego do Rio Grande para a dinâmica hidrogeomorfológica do Ribeirão do Chiqueiro. Neste sentido, as características de cada curso d'água ficam em segundo plano, sendo dada ênfase à avaliação do papel do tributário no fornecimento de carga sedimentar e na alteração morfológica do curso principal. Assim, serão descritos apenas os fatores que influenciam diretamente na configuração hidrogeomorfológica antes e depois da confluência.

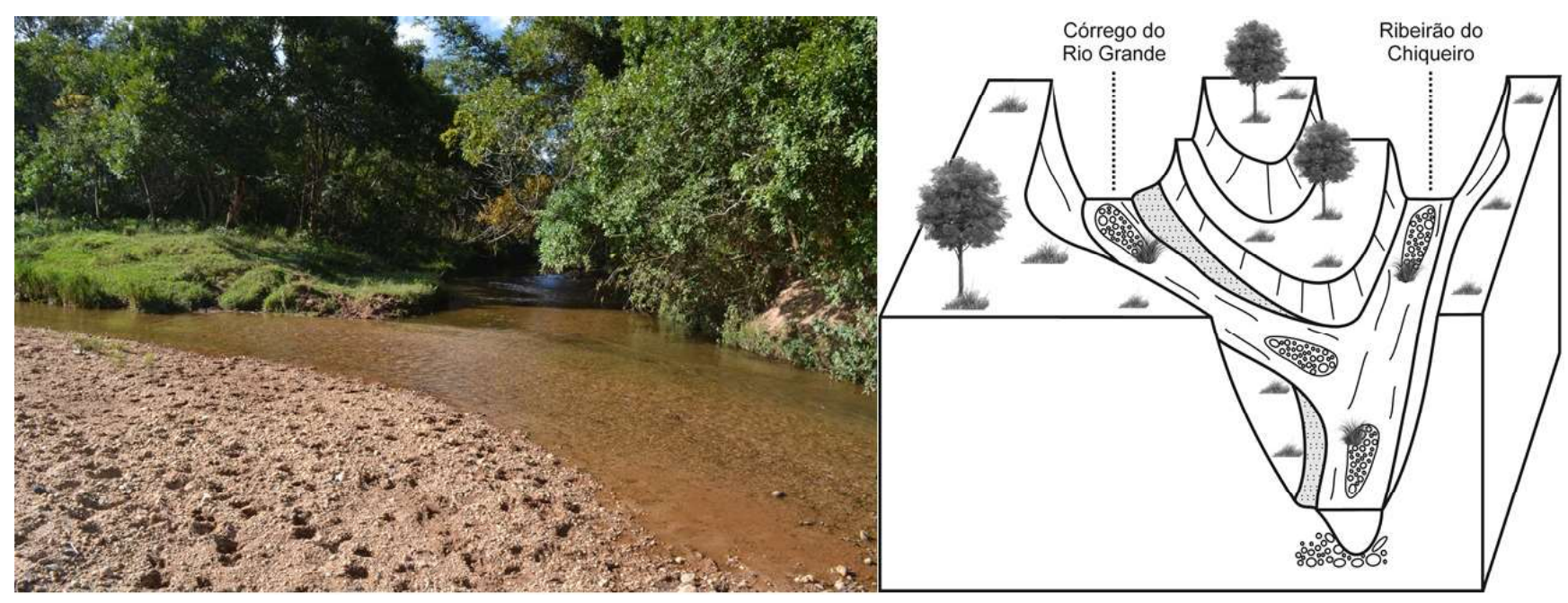

Figura 9 - Foto e bloco diagrama da confluência do Córrego do Rio Grande com o Ribeirão do Chiqueiro. Fonte: Elaboração dos autores.

O trecho do Córrego do Rio Grande percorrido antes da confluência possui configuração similar à do primeiro segmento investigado, tanto em morfologia de leito (predomínio de poço-corredeira) quanto em relação aos ambientes marginais. $\mathrm{O}$ trecho no Ribeirão do Chiqueiro à montante da confluência, por sua vez, apresenta carga de leito composta principalmente por areia, com pouca presença de seixos e cascalhos, além de possuir o vale mais encaixado.

O material mais grosso após a confluência condiciona a profundidade da zona de escavação e a morfologia à jusante desta. Devido à presença de seixos e cascalhos, este trecho passa a ser em poço-corredeira. Bueno et al. (1997) já apontavam para o fornecimento de carga detrítica pelo Córrego do Rio Grande para o Ribeirão do Chiqueiro após a confluência. A carga de fundo - que serve de ligação entre a estrutura do fluxo e a morfologia do leito (SANTOS \& STEVAUX, 2017) - é condicionada pelo tributário, no caso o Córrego do Rio Grande, fazendo com que o Ribeirão do Chiqueiro passe a ter a morfologia em poço-corredeira, o que não é visualizado no curso principal antes da confluência. 
Implicações do encouraçamento das calhas fluviais para a morfodinâmica recente/atual dos cursos d'água

As distintas configurações de fundo de vale ao longo do Córrego do Rio Grande permitem diferentes reflexões acerca do papel dos pavimentos detríticos para a configuração morfológica e morfodinâmica dos cursos d'água. A simples presença dos clusters na calha fluvial altera as condições de fluxo, proporcionando um rearranjo na disposição deste material grosso no leito. O fluxo d'água converge quando entra em contato com o material mais grosso (corredeira), enquanto o mesmo diverge após superar o pavimento detrítico (poço) (FERNANDEZ, 2009). Essa dinâmica de fluxo faz com que as corredeiras se configurem como feições de leito menores e mais confinadas espacialmente quando comparadas com os poços (FERNANDEZ et al., 2002; MILAN, 2013).

Essas dimensões hidrológicas são as responsáveis por desenvolverem a morfologia em poço-corredeira, cujos clusters podem adquirir diversas configurações espaciais que, por sua vez, são determinadas pelas condições de fluxo atuantes (STROM et al., 2005; HENDRICK et al., 2010; HEAYS, 2011). Deste modo, mesmo que durante seu processo de formação os clusters estejam dispostos linearmente ao longo do vale (sem a presença de poços), a dinâmica fluvial (ação do fluxo) condiciona um rearranjo na distribuição espacial deste material, favorecendo a formação de morfologia em poço-corredeira.

Com base neste pressuposto, é possível inferir que os conceitos comumente trabalhados na literatura, que associam encouraçamento à simples presença de um material imóvel ou temporariamente imóvel in situ (BRIDGE, 2003; ALMEDEIJ \& DIPLAS, 2005; VERICAT et al., 2006; GOUDIE, 2004; FRINGS, 2008) são limitados sob a ótica geomorfológica. A própria ação do fluxo altera, sazonalmente ou não, a disposição espacial dos clusters (BILLI, 1988) e favorece a formação de morfologia de poço-corredeira (MONTGOMERY \& BUFFINGTON, 1997). Um pequeno segmento fluvial rugoso sob a proposta conceitual acima referenciada poderia ser considerado como encouraçado, no entanto, em uma análise tangente à geomorfologia tal definição não se adequa por completo, muito em decorrência de não contribuir para reflexões acerca das consequências da presença destes clusters para a morfologia e para a morfodinâmica dos canais.

Contribuições neste sentido são feitas por Montgomery \& Buffington (1997), Magalhães Júnior et al. (2008) e Messias \& Magalhães Júnior (2014), associando processos de encouraçamento à morfologia de poço-corredeira. Nesta perspectiva, portanto, somente os pavimentos detríticos que condicionam alterações na morfologia do leito se configurariam como encouraçados. Os seixos e cascalhos imóveis no segundo segmento (trecho em rochas intrusivas), por exemplo, não se enquadram nesta proposição, pois não se encontram auto suportados. Eles permanecem imóveis pelo contato com o material intrusivo que, por sua vez, atua como pequenas soleiras retendo o material mais grosso. Assim, são as intrusões que controlam a dinâmica hidrológica primordialmente, e não os seixos e cascalhos, gerando a morfologia em step-pools.

Consoante, somente o primeiro, terceiro e quarto segmento se configuram como encouraçados considerando a morfologia do leito, tendo em vista que evidências de campo apontam que o pavimento detrítico condiciona primordialmente as condições de fluxo, ou seja, formam uma morfologia de poço-corredeira nestes trechos.

Apesar do contínuo debate sobre os mecanismos que garantem a manutenção da configuração poçocorredeira (THOMPSON, 2011), a hipótese da reversão da velocidade do fluxo (KELLER, 1971 apud FERNANDEZ et al., 2002) estabelece que, em condições de maior vazão, a velocidade do fluxo é maior nos poços, escavando-os (MILAN, 2013) e tornando o leito longitudinalmente caracterizado por pequenos degraus (Figura 10).

Essa condição hidrossedimentológica garante a manutenção das formas no leito (poços e corredeiras). Durante o período de maior vazão as corredeiras atuam como zonas de amortecimento para os sedimentos provenientes da escavação dos poços, enquanto no período de menor vazão os poços recebem os materiais de granulometria mais fina provenientes do transporte seletivo que ocorre nas corredeiras (FERNANDEZ et al., 2002; MILAN, 2013), gerando ondulações no perfil longitudinal (FERNANDEZ, 2009).

Inferências acerca do rebatimento dos pavimentos detríticos para a morfodinâmica fluvial são complexas, muito em decorrência da não aceitação de uma única 
hipótese para sua explicação ou pelo não entendimento do papel dos fluxos turbulentos para a dinâmica fluvial (STORM et al., 2005; MILAN, 2013). Fernandez et al. (2002) afirmam que a origem dos sistemas poços-corredeiras está associada à dinâmica hidrossedimentológica associada ao processo de meandramento, sendo que as corredeiras se situam nas áreas de inflexão dos meandros e os poços nas curvas (Figura 10 - A).

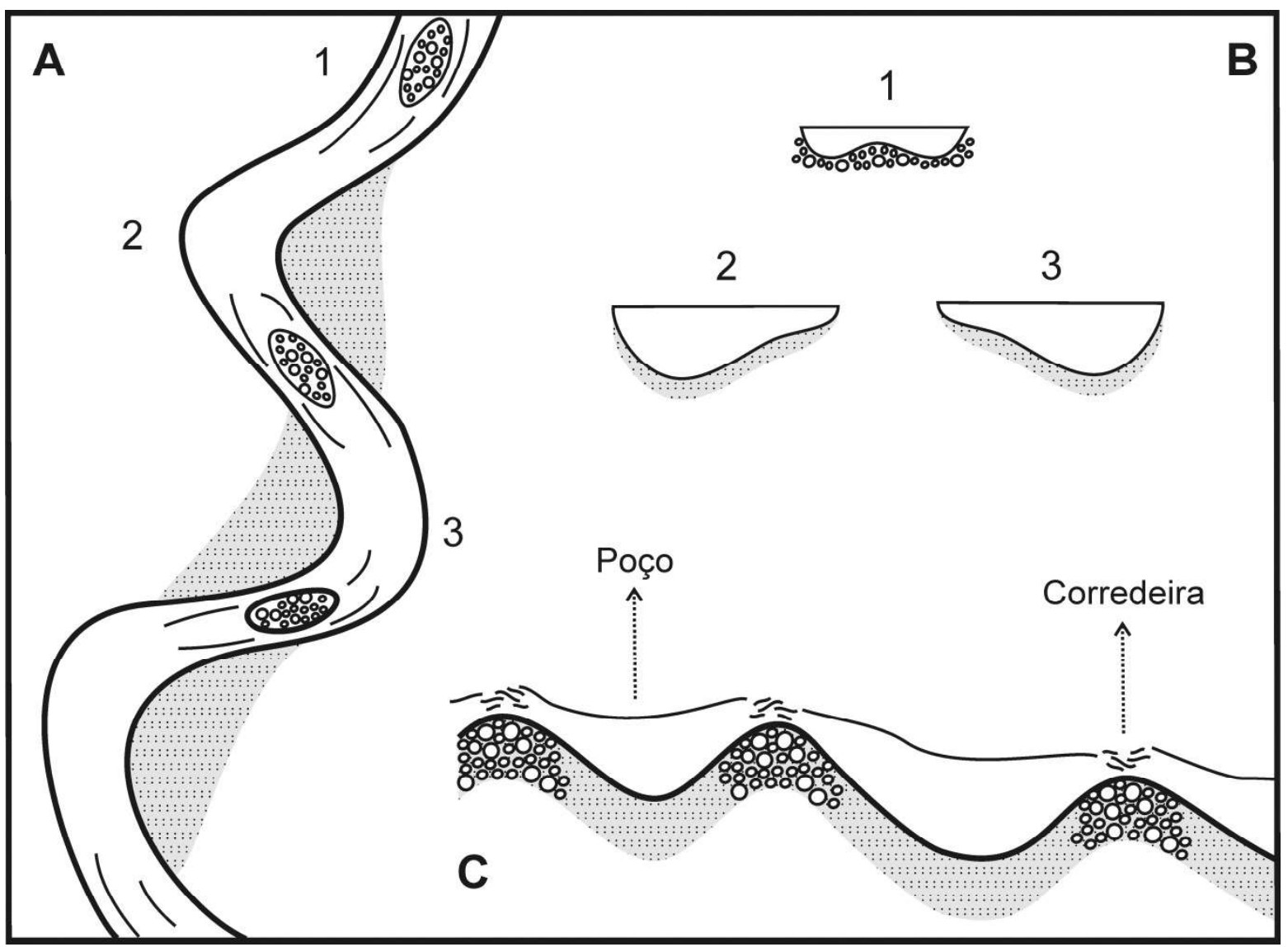

Figura 10 - Morfologia em poço-corredeira. Fonte: Adaptado de Dunne \& Leopold (1978), Church (1992) e Gilmore Creek Restoration (2013).

Como os pavimentos detríticos não correspondem à capacidade e competência dos fluxos contemporâneos, as taxas de incisão vertical do canal cessam ou diminuem (FRINGS, 2008; GRANT, 2012), fazendo com que os cursos d'água dispensem sua energia migrando lateralmente e erodindo as margens (VERICAT et al., 2006). Deste modo, pode tornar-se sinuoso.

A associação da sinuosidade do canal com o padrão meandrante deve ser feita com cautela, tendo em vista a necessidade da consideração conjunta entre morfologia e os aspectos hidrossedimentológicos (PETTS \& FOSTER, 1985). Entretanto, no primeiro, terceiro e quarto segmentos, os processos de erosão na margem côncava e deposição na margem convexa (planícies e barras laterais) denotam processos de meandramento.

A presença de material arenoso sobreposto à fácies basal de seixos evidencia uma mudança na sedimentação que apresentava, anteriormente, características de ambiente de calha (fácies basal). Por processos de migração/acresção lateral, desenvolveramse feições deposicionais de matriz arenosa como de planícies e barras laterais (MIALL, 1985; BRISTOW \& BEST, 1993). Essa evolução pode indicar uma possível redução na capacidade e competência atual do Córrego do Rio Grande.

Se o encouraçamento for considerado o processo responsável pelos pavimentos detríticos que condicionam a morfodinâmica e a morfologia dos cursos d'água (viés geomorfológico), é possível inferir que, para a área de estudo, foram identificados três trechos encouraçados: o primeiro, terceiro e quarto segmentos fluviais. Essa afirmação considera que os seixos e cascalhos imóveis em ambientes de calha nos trechos referidos impedem, mesmo que parcialmente, a incisão vertical do canal 
e favorecem sua migração lateral (morfodinâmica). Em um processo de retroalimentação, os sedimentos e o processo de migração lateral condicionam e são condicionados pelo sistema poço-corredeira (morfologia).

Deste modo, os pavimentos detríticos encontrados no segundo segmento fluvial não se configuram como encouraçados, tendo em vista que os seixos e cascalhos que se encontram imóveis na calha não condicionam, de maneira significativa, a morfodinâmica e a morfologia do canal. Neste caso, as intrusões de rochas metabásicas são responsáveis por definir as condições de fluxo e, consequentemente, a morfologia (step-pools) e a morfodinâmica (encaixado e retilíneo) do curso d'água.

\section{Considerações Finais}

Investigações geomorfológicas que objetivem análises mais integradas acerca do papel dos pavimentos detríticos para a morfologia e para a morfodinâmica do canal se apresentam como um desafio em face aos conceitos comumente utilizados. Nesse sentido, a investigação dos pavimentos detríticos presentes ao longo do Córrego do Rio Grande possibilitou estabelecer as consequências da presença dos pavimentos detríticos para a morfologia e para a morfodinâmica do curso d'água.

Evidências de campo apontam que no primeiro, terceiro e quarto segmentos fluviais investigados, os clusters dispostos em ambiente de calha condicionam, pelas condições de fluxo no contato com os pavimentos detríticos, a morfologia do canal em poço-corredeira e sua morfodinâmica sinuosa. Não obstante, baseado em aspectos hidrossedimentares atuantes (erosão na margem côncava e deposição na margem convexa), o papel de sua morfodinâmica resulta no padrão fluvial meandrante.

O segundo segmento, por sua vez, apresenta indícios da morfodinâmica e da morfologia fluvial controlada pelas intrusões de rochas metabásicas, ou seja, não são os seixos e cascalhos que definem, primordialmente, a relação entre a estrutura sedimentar e as condições de fluxo, mas sim o material intrusivo. Dessa forma, é o maior controle do arcabouço geológico que irá definir a morfodinâmica retilínea e a morfologia em step-pools.

Consoante, considerando o conceito de encouraçamento como o adotado comumente na literatura, pela simples presença de material mais grosso e imóvel em ambiente de calha, todos os trechos investigados estariam encouraçados. Entretanto, se considerado as alterações dos clusters para a morfologia e para a morfodinâmica do canal, somente o primeiro, terceiro e quarto segmentos fluviais encontram-se encouraçados, o que sob a ótica geomorfológica faz mais sentido, tendo em vista que permite analisar o rebatimento do material de calha na morfologia e na morfodinâmica fluvial.

A definição de um conceito tangente à geomorfologia para o estudo dos processos de encouraçamento, portanto, ainda está em aberto, sendo necessárias pesquisas em outros domínios geológico-geomorfológicos para determinar se a ocorrência dos pavimentos detríticos podem gerar outras alterações na morfodinâmica do canal fluvial para além da migração lateral e do meandramento, e na morfologia para além do sistema poço-corredeira.

\section{Agradecimentos}

Os autores agradecem ao Conselho Nacional de Desenvolvimento Científico e Tecnológico (CNPq) pelo apoio com a concessão de bolsa (modalidade GM) e ao Grupo de Pesquisa Geomorfologia e Recursos Hídricos (CNPq/UFMG).

\section{Referências Bibliográficas}

ALMEDEIJ, J.; DIPLAS, P. Bed load sediment transport in ephemeral and perennial gravel bed streams. Eos, v. 86, n. 44, p. 429-434, 2005.

ALMEIDA-ABREU, P. A. O Supergrupo Espinhaço da Serra do Espinhaço Meridional (Minas Gerais): O Rifte, a Bacia e o Orógeno. Geonomos, v. 3, n. 1, p. 1-18, 1995.

AUGUSTIN, C. H. R. R.; FONSECA, B. M.; ROCHA, L. C. Mapeamento Geomorfológico da Serra do Espinhaço Meridional: primeira aproximação. Geonomos, Belo Horizonte, v. 19, n. 2 , p. $50-90,2011$.

BARROS, L. F. P.; COE, H. H. G.; SEIXAS, A. P.; MAGALHÃES JÚNIOR, A. P.; MACARIO, K. C. D. Paleobiogeoclimatic scenarios of the Late Quaternary inferred from fluvial deposits of the Quadrilátero Ferrífero (Southeastern Brazil). Journal of South American Earth Sciences, v. 67, p. 71-88, 2016.

BENN, P. C.; ERSKINE, W. D. Complex channel response to flow regulation: Cudgegong river below Windamere Dam, Australia. Applied Geography, v. 14, p. 153-168, 1994.

BILLI, P. A note on cluster bedform behavior in a gravel-bed river. Catena, v. 15, p. 473-481, 1988. 
BRIDGE, J. S. Rivers and Floodplains. Blackwell Science, Oxford, 2003. 492 p.

BRIERLEY, G. J.; FRYIRS, K. A. Geomorphology and River Management: Applications of the River Styles Framework. Oxford, UK: Blackwell Publications, 2005. 398 p.

BRISTOW, C. S.; BEST, J. L. Braided Rivers: Perspectives and Problems. In: BRISTOW, C.

S.; BEST, J. L. (org.). Braided Rivers. Londres: Geological Society of London Special Publication 75, 1993. p 1-11.

BUENO, G. T.; TRINDADE, E. S.; MAGALHÃES JÚNIOR, A. P. Paleociclos deposicionais e a moderna dinâmica fluvial do Ribeirão do Chiqueiro - Depressão de Gouveia/Espinhaço Meridional - MG. Geonomos, v. 5, n. 2, p. 15-19, 1997.

CHARLTON, R. Fundamentals of fluvial geomorphology. London; New York: Routledge, 2008. 234 p.

CHIN, A. The morphologic structure of step-pools in mountain streams. Geomorphology, v. 27, p. 191-204, 1999.

CHURCH, M. Channel morphology and typology. In: CALOW, P.; PETTS, G. E. (org.). The rivers handbook: Hydrological and ecological principles. Oxford: Wiley-Blackwell, 1992, p. 126-143.

CURRAN, J. C.; TAN, L. An investigation of bed armouring process and the formation of microclusters. In: Joint Federal Interagency Conference, 2., 2010, Las Vegas (EUA). Anais do 2nd Joint Federal Interagency Conference, Las Vegas: [s.n.], 2010, Não paginado.

DUNNE, T.; LEOPOLD, L. B. Water in Environmental Planning. San Francisco: W. H. Freeman, 1978. 818 p.

EMMETT, W. W.; WOLMAN, M. G. Effective discharge and gravel-bed rivers. Earth Surface Processes and Landforms, v. 26, p. 1369-1380, 2001.

FERNANDEZ, O. V. Q. Discriminação de habitats aquáticos no Córrego Guavirá, Marechal Cândido Rondon (PR). Geografias, v. 5, n. 1, p. 22-36, 2009.

FERNANDEZ, O. V.; Q. SANDER, C.; REBELATTO, G. E. Sequência de Soleiras e Depressões no Córrego Guavirá, Marechal Cândido Rondon, Região Oeste do Paraná. Revista Brasileira de Geomorfologia, v. 3, n. 1, p. 49-57, 2002.

FRINGS, R. M. Downstream fining in large sand-bed rivers. Earth-Science Reviews, v. 87, p. 39-60, 2008.

GILMORE CREEK RESTORATION. Creating Pools and Riffles. [Blog], 2013. Disponível em: <http:// gilmorecreekrestoration.blogspot.com.br/2013/11/creatingpools-and-riffles.html?view=flipcard $>$. Acesso em: 20/03/2018.

GOMEZ, B. Temporal variations in bedload transport rates: The effect of progressive bed armouring. Earth Surface Processes and Landforms, v. 8, p. 41-54, 1983.

GOUDIE, A. S. Encyclopedia of Geomorphology. Londres: Routledge, 2004. 1156 p.

GRANT, G. E.; SWANSON, F. J.; WOLMAN, M. G. Pattern and origin of stepped-bed morphology in high-gradient streams, Western Cascades, Oregon. Geological Society of America Bulletin, v. 102, p. 340-352, 1990.

GRANT, G. E. The geomorphic response of gravel-bed rivers to dams: perspectives and prospects. In: $\mathrm{CHURCH}, \mathrm{M}$; BIRON, P. M.; ROY, A. G. (org.). Gravel-Bed Rivers: Processes, Tools, Environments. Chichester: Wiley, 2012, p. 165-181.

HEAYS, K. G. Cluster formation and Stream-bed Armouring: A photogrammetric study. 2011. Tese (Doutorado) - The University of Auckland, Auckland (Nova Zelândia), 2011.

HENDRICK, R. R.; ELY, L. L.; PAPANICOLAU, A. N. The role of hydrologic processes and geomorphology on the morphology and evolution of sediment clusters in gravel-bed rivers. Geomorphology, v. 114, n. 3, p. 483-496, 2010.

KELLER, E. A. Areal sorting of bed load material: the hypothesis of velocity reversal. Bulletin of the Geological Society of America, v. 82, p. 753-756, 1971.

LARONNE, J. B.; REID, I.; YITSHAK, Y.; FROSTICK L. E. The non-layeringof gravel streambeds under ephemeral flood regimes. Journal of Hydrology, v. 159, p. 353-363, 1994.

LEÃO, M. R.; REZENDE, E.A.; SALGADO, A. A. R.; NALINI JÚNIOR, H. A. Erosão, denudação e evolução do relevo na média Serra do Espinhaço Meridional, Minas Gerais. Revista Brasileira de Geomorfologia, v. 13, n. 2, p. 113-124, 2012.

LEOPOLD, L. B.; WOLMAN, M. G.; MILLER, J. P. Fluvial Processes in Geomorphology. San Francisco: Freeman and Company, 1964. 522 p.

MAGALHÃES JÚNIOR, A. P.; BARROS, L. F. P.; FELIPPE, M. F. Southern Serra do Espinhaço: The Impressive Plateau of Quartzite Ridges. In: VIEIRA, B. C.; SALGADO, A. A. R.; SANTOS, L. J. C. (org.). Landscapes and Landforms of Brazil. London: Springer, 2015. p. 359-370.

MAGALHÃES JÚNIOR, A. P.; SANTOS, G. B.; CHEREM, L. F. S. Processos de Encouraçamento da Calha do Alto Rio das Velhas e seus Reflexos na Dinâmica Fluvial Moderna, 
Quadrilátero Ferrífero, MG. In: II Encontro Latino Americano de Geomorfologia e VII Simpósio Nacional de Geomorfologia, 2008, Belo Horizonte. Anais do VII SINAGEO. Belo Horizonte: Tec Art, 2008. v. 1. p. 120-130.

MESSIAS, R. M.; MAGALHÃES JÚNIOR, A. P. Níveis deposicionais aluviais no vale do Córrego do Rio Grande, Depressão de Gouveia - MG. Revista Geonorte, v. 10, n. 379384, 2014.

MIALL, A. D. Architectural-element analysis: a new method of facies analysis applied to fluvial deposits. Earth Science Review, v. 22, n. 4, p. 261-308, 1985.

MILAN, D. J. Sediment routing hypothesis for pool-riffle maintenance. Earth Surface Processes and Landforms, v. 38, n. 14, p. 1623-1641, 2013.

MONTGOMERY, D. R.; BUFFINGTON, J. M. Channel-reach morphology in mountain drainage basins. Geological Society of America Bulletin, v.109, p. 596-611, 1997.

PETTS, G. E. \& FOSTER, D. L. Rivers and Landscape. Londres: Edward Arnold, 1985. 274 p.

REZENDE, E. A.; LEÃO, M. R.; SALGADO, A. A. R.; OLIVEIRA, C. K. R.; NALINI JÚNIOR, H. A. A influência litológica nas taxas de denudação geoquímica do Médio Espinhaço Meridional - MG. Sociedade \& Natureza, v. 22, n. 3, p. 503-514, 2010.

ROSGEN, D. L. A classification of natural rivers. Catena, v. 22, p. 169-199, 1994.

SAADI, A. A geomorfologia da Serra do Espinhaço em Minas Gerais e de suas margens. Geonomos, v. 3, n. 1, p. 41-63, 1995.

SALGADO, A. A. R. Desnudação Geoquímica e Evolução do Relevo no Espinhaço Meridional - MG. 2002. Dissertação (Mestrado em Análise Ambiental) - Instituto de Geociências, Universidade Federal de Minas Gerais, Belo Horizonte, 2002.
SALGADO, A. A. R.; VALADÃO, R. C. Contribuição da Desnudação Geoquímica para a Erosão diferencial no Espinhaço Meridional/MG. Revista Brasileira de Geomorfologia, v. 4, n. 2, p. 31-40, 2003.

SANTOS, G. B.; MAGALHÃES JÚNIOR, A. P.; AZEVEDO, F. W. Taxas e Processos de Evolução de Margens Fluviais no Alto Rio das Velhas, Quadrilátero Ferrífero, MG. In: II Encontro Latino Americano de Geomorfologia e VII Simpósio Nacional de Geomorfologia, 2008, Belo Horizonte. Anais do VII SINAGEO. Belo Horizonte: Tec Art, 2008. v. 1. p. 240-250.

SANTOS, V. C.; STEVAUX, J. C. Processos fluviais e morfologia em confluências de canais: uma revisão. Revista Brasileira de Geomorfologia, v. 18, p. 03-17, 2017.

SCHUMM, S. A.; KAHN, H. Experimental study of channel patterns. Bulletin of the Geological Society of America, v. 83, p. 1755-1770, 1972.

STEVAUX, J.C.; PAES, R. J.; FRANCO,A.A.; ETCHEBEHERE, M. L.; FUJITA, R. H. Morphodynamics in the confluence of large regulated rivers: the case of Paraná and Paranapanema rivers. Latin American Journal of Sedimentology and Basin Analysis. v. 16, n. 2, p. 101-109, 2009.

STROM, K. B.; PAPANICOLAU, A. N.; BILlinG, B.; ELY, L. L.; HENDRICKS, R. R. Characterization of particle cluster bedforms in a mountain stream. In: World Water and Environmental Resources Congress, 2005, Anchorage, Alaska, United States. Anais do World Water and Environmental Resources Congress. [s.1.]: [s.n], 2005, p. 1-12.

THOMPSON, D. M. The velocity-reversal hypothesis revisited. Progress in Physical Geography, v. 35, n. 1, p. 123-132, 2011. VERICAT, D.; BATALLA, R. J.; GARCIA, C. Breakup and reestablishment of the armour layer in a large gravel-bed river below dams: The lower Ebro. Geomorphology, v. 76, p. 122136, 2006. 